\title{
Uso de jogos de celular no aprendizado de Física no ensino fundamental: Um estudo exploratório do uso do jogo Angry Birds Space no ensino do conteúdo de Lançamento de Projéteis.
}

Savana dos Anjos Freitas - ULBRA, Canoas/RS.savanafreitas_@hotmail.com Agostinho Serrano de Andrade Neto - ULBRA, Canoas/RS.asandraden@gmail.com Vinicius Gouveia Silva - ULBRA, Canoas/RS. vinicius.golveia@souzacruz.com.br

\section{RESUMO}

$\mathrm{O}$ aprendizado de Física no ensino fundamental tem sido deixado em segundo plano no Brasil, tanto dentro da pesquisa em ensino como da prática em sala de aula. A estrutura curricular presente no país contempla o ensino específico de Física apenas a partir do ensino médio. Neste artigo, trazemos um estudo exploratório onde foram utilizados jogos de celular (em particular o Jogo Angry Birds Space) no ensino de lançamento horizontal e oblíquo e do conceito de gravidade. O estudo foi desenvolvido em uma escola municipal da região metropolitana de Porto Alegre, em um bairro de baixo poder aquisitivo por acadêmicos do PIBID de uma universidade privada da mesma região. Os alunos realizaram uma série de atividades que girou em torno de jogar o Angry Birds Space de forma individual e competitiva com outros estudantes, durante um período de um semestre. Em seguida foram entrevistados dentro do protocolo Report Aloud e seus gestos descritivos foram analisados. Para análise, escolhemos o referencial teórico da Teoria da Mediação Cognitiva (TMC). Para discussão neste artigo, escolhemos dois estudantes e analisamos seu discurso verbal e gestual. Como resultado, argumentamos que os estudantes adquiriram imagens mentais e drivers que os permitem prever com boa precisão trajetórias com ângulo de lançamento e velocidade de lançamento diferentes, porém, com pouca ou quase nenhuma modificação no seu conceito de gravidade.

Palavras-Chave: Angry Birds Space, Jogos, Ensino de Física, Imagens Mentais, Teoria da Mediação Cognitiva

\section{Use of Mobile Games in the learning of Physics in fundamental school in Brazil: An exploratory study of the game Angry Birds Space in teaching the projectile movement.}

\begin{abstract}
Learning Physics in fundamental school has been left to a secondary plan in Brazil, as much as within the physics education research community as much as within the classroom. The established curriculum structure in the country introduces Physics only from the high school years. In this paper, we discuss an exploratory study in which mobile games were used (in particular the Angry Birds Space game) when teaching projectile movement (vertical and oblique movement) and the concept of gravity. The study was developed in a municipal school of the Grand Porto Alegre, in a low income neighborhood school by physics undergraduate students of the PIBID (State Funded Scholarship for Introductory Teaching Programme) of a private university of said region. The students made a series of activities that were centered around playing Angry Birds Space individually and competing with the other students during a period of a V. $14 \mathrm{~N}^{\mathrm{o}} 1$, julho, 2016
\end{abstract}


semester. After this stage they were interviewed within the report aloud protocol and their depictive gesture were analyzed. For the analysis, we picked the Cognitive Mediation Networks Theory (CNMT). To discuss in this contribution, we picked two students and analyzed their verbal and gesture speech. As results, we argue that the students acquired mental images and drivers that allowed them to predict with fair precision trajectories with different launching and total velocity angles, albeit with fairly no change in their gravitation concept.

Keywords: Angry Birds Space, Games, Physics Teaching, Mental Images, Cognitive Networks Mediation Theory

\section{Introdução}

O lançamento de projéteis é uma temática de grande importância histórica e atual, desde as catapultas que eram utilizadas nas Guerras Dácias entre o império romano e Dacia (101-102 e 105-106 D.C.), na Primeira Guerra mundial, onde foram empregadas por tropas francesas contra os alemães, e até hoje nos lançamentos de foguetes, em modalidades esportivas, onde diferentes objetos são arremessados e também na caça, muito comum nos povos indígenas.

A explicação aristotélica do movimento de projéteis (NEVES, 2000) argumentava que depois da perda de contato com o projetor - que poderia ser um estilingue ou catapulta - a continuação do movimento era explicado da seguinte maneira: quando se movimenta, o projétil passa a ocupar o lugar que antes era preenchido pelo ar que havia à sua frente. Este mesmo ar, por sua vez, flui em torno da pedra para ocupar o espaço vazio deixado pela mesma. Com este movimento o ar impele o objeto para frente.

Este processo é denominado antiperistasis, além disso, ele imaginou outra maneira deste meio agir sobre o objeto para entrar em movimento, seria como este meio conseguisse uma determinada "força", um "poder", uma capacidade onde fizesse que o objeto entrar em movimento, a partir do projetor(que com a ajuda do ar, coloca em movimento), ou do dele próprio.

A explicação de Hiparco (PEDUZZI \& PEDUZZI, 1988), difere da aristotélica. Para ele, existe uma força que é transmitida e que fica armazenada no projétil (força impressa), quando é arremessado e com o passar do tempo esta força interna vai diminuindo. Por mais que estes dois gregos discordem de como ocorre o lançamento de projéteis, ambos acreditavam descreviam o movimento de um projétil em uma trajetória retilínea .

O filósofo francês, Jean Buridan (1300-1358), relatou o ímpeto dado pelo impulsor na velocidade do corpo em movimento (ROONEY, 2013), o que ele imaginava é parecido com o conceito que hoje chamamos de momentum, ele defendia que um projétil adquire um ímpeto quando arremessado, fazendo assim, produzir o movimento, o que fazia diminuir a intensidade das forças, seria o ímpeto, que ficava armazenado, dentro do projétil. Este filósofo, defendia que a velocidade era relacionada com a quantidade de matéria.

A pesquisa que foi realizada no final do ano de 2014 em um escola pública da escola de Canoas, através do projeto PIBID(Programa Institucional de Bolsas de Iniciação à Docência), teve como objetivo responder a seguinte pergunta-chave: $\mathbf{O}$ uso do jogo Angry Birds Space contribui na modificação das imagens mentais, drivers e conceitos utilizados para resolver problemas de lançamentos de projéteis em 
estudantes do ensino fundamental? O projeto durou o último semestre, com duas turmas de sexto ano no turno da tarde.

O jogo Angry Birds já está sendo utilizado em sala de aula por professores (EXTRA GLOBO, 2014; TERRA NOTICIAS, 2014) e tem despertado, dentro os pesquisadores em ensino, a curiosidade de sua potencialidade para o ensino de Física.

\section{Referencial teórico}

Nossa pesquisa utilizou como arcabouço teórico a Teoria da Mediação Cognitiva em Rede - TMC (SOUZA, 2004; SOUZA et al., 2012), que procurou explicar o processamento da informação pelo cérebro, propiciando uma abordagem ampla para a cognição humana.

A TMC foi fundamentada em cinco premissas relativas à cognição humana e ao processamento de dados:

(...) 1) A espécie humana tem como maior vantagem evolutiva a capacidade de gerar, armazenar, recuperar, manipular e aplicar o conhecimento de várias maneiras; 2) Cognição humana é efetivamente o resultado de algum tipo de processamento de informação; 3) Sozinho, o cérebro humano constitui um finito e, em última instância, insatisfatório, recurso de processamento de informação; 4) Praticamente qualquer sistema físico organizado é capaz de executar operações lógicas em algum grau; 5) Seres humanos complementam o processamento da informação cerebral por interação com os sistemas físicos externos organizados. (SOUZA et al., 2012, p.2, tradução nossa).

A cognição humana é o resultado de processamento de informações, e uma parte importante dessa atividade é realizada fora do cérebro, visto ser ele limitado para elaborar todas as informações disponíveis. Nesse sentido, utilizamos o processamento externo por meio da interação com estruturas do ambiente para aumentar a capacidade de processamento de informações.

Por exemplo, quando usamos um computador para processar informações, ou mesmo realizar um cálculo mais complexo, o estamos utilizando como um mecanismo externo de mediação. Para tanto, precisamos construir alguns mecanismos internos em nossa estrutura cognitiva que nos possibilite manusear esse computador e compreender não somente seu funcionamento, mas também as informações que ele está nos oferecendo. São os mecanismos internos que tornam possível o emprego dos mecanismos externos, e esses mecanismos internos são chamados pelo autor da TMC de "drivers", os quais se desenvolvem a partir da interação entre o indivíduo e o mecanismo externo de processamento de informações por meio do método processo piagetiano de equilibração.

Isso significa que, para garantir o processo de mediação cognitiva com um mecanismo externo, nosso cérebro cria novos drivers que o dotam de competências específicas para se comunicar com esse mecanismo. Com isso, adquire um ganho de processamento de informações que se mantém mesmo que a conexão com o mecanismo externo seja interrompida. E esse ganho é considerado aquisição de conhecimentos pelo autor da TMC .

Talvez a premissa mais interessante da TMC para nossa pesquisa seja que o cérebro busca instrumentos externos capazes de completar suas limitações naturais, como no desenvolvimento histórico da química computacional. Esse processo de 
mediação resulta na aquisição de uma competência representacional advinda da construção de representações e drivers, ampliando sobremaneira a capacidade de processar informações do cérebro. Diante disso, optamos neste artigo por mostrar os indícios da presença dessas representações e desses drivers provenientes do processo de mediação cognitiva extracerebral. Em trabalho recente, Rocha e Serrano (2013) mostraram que a TMC também se encaixa muito bem para explicar as modificações cognitivas resultantes do uso de simulações na área da Física.

\section{Problema de pesquisa e metodologia}

O jogo escolhido é um dos últimos lançado da serie Angry Birds, que se tornou mundialmente conhecida em poucos anos. O jogo apresenta uma historia bem simples, alguns pássaros estão com raiva de porcos verdes que roubaram seus ovos e acabam se escondendo através de diversos materiais, como a madeira, o vidro e concreto, o jogador devera usar um estilingue para jogar pássaros e assim, podendo atingir os porcos que estão bloqueados por estes materiais. Como foi um grande sucesso, logo em seguida a empresa lançou uma continuidade para a séria como Angry Birds Seasons, Angry Birds Rio, Angry Birds Star Wars I e II e por último o Angry Birds Space. Este último é o que usamos para desenvolver no projeto, o jogo foi criado em parceria com a NASA(Agencia Espacial Americana), onde tem o mesmo objetivos dos demais, só que com a diferencia que é realizado no espaço, neste jogo, os jogadores deverão saber lidar com a gravidade e a atmosfera dos planetas entre outras leis da Física que irão mudar completamente o jogo.

A metodologia que sustenta os resultados da nossa pesquisa é do tipo microetnográfica* (MOREIRA, 2002). Os dados para análise consistem em: testes escritos (pós-teste), vídeo das entrevistas e a transcrição das mesmas com a identificação e explicação de todos os gestos descritivos realizados pelos estudantes quando narravam os processos de raciocínio para a resolução das questões dos testes escritos.

As entrevistas foram conduzidas segundo o protocolo Report Aloud, adaptado por nós do protocolo Think Aloud (VAN-SOMEREN et al., 1994). O protocolo Report Aloud difere do protocolo Think Aloud apenas no momento em que o pesquisador busca compreender o processo de raciocínio dos estudantes na resolução de problemas. Enquanto o método Think Aloud explora os processos de pensamento dos alunos no ato da resolução do problema, interferindo nesse processo, o método Report Aloud o faz após o estudante ter resolvido o problema. Dessa forma, não há a interferência do pesquisador no próprio processo de raciocínio do estudante e o resgate fidedigno desse raciocínio é possível, a depender da habilidade do pesquisador em explorar as representações e os drivers existentes na estrutura cognitiva dos estudantes , identificando quais já existiam (conhecimento tácito) e quais foram adquiridas ao longo do curso.

Em nossa pesquisa, o conhecimento tácito é a base fundamental de análise, junto com o conhecimento explícito do discurso do estudante durante as entrevistas. Ao se deparar com uma atividade de resolução de problemas, ele irá evocar um conjunto de

\footnotetext{
A microetnografia é uma etnografia focada, que se ocupa de observar de forma repetida e analisar com detalhes registros audiovisuais de interações humanas em cenaschaves, acompanhadas de uma observação participativa do contexto mais amplo onde estas interações ocorrem. É uma etnografia da comunicação (verbal e não-verbal) enfocando sujeitos individuais e seu discurso em certos cenários.
} 
conhecimentos prévios e, conforme já argumentamos, boa parte dele é tácito. Naturalmente é impossível a análise do conhecimento tácito se este não for transformado em explícito. Por isso, resolvemos focar de modo especial no conhecimento tácito que se apresenta como imagens mentais, pois entendemos que, dessa maneira, os conhecimentos tácitos são transformados em explícitos por elementos específicos, diretos e indiretos, do discurso do estudante, sobretudo sob a forma de gestos descritivos.

Para analisar os gestos descritivos utilizamos como base a linha de trabalho que revela o conhecimento implícito inerente à visualização interna, mediante externalização por análise gestual (MONAGHAN; CLEMENT, 1999). A partir dessa metodologia, é possível identificar padrões de gestos e relacioná-los com os conhecimentos implícitos existentes na estrutura cognitiva dos estudantes (CLEMENT; STEPHENS, 2010). O que Clement e Stephens chamam de imagens mentais e simulações mentais interpretamos aqui, no contexto de nosso referencial teórico, como representações e drivers.

As duas turmas tinham perfil completamente diferentes, o $6^{\circ} \mathrm{C}$, era formado por crianças que estavam na idade adequada para a série, enquanto o $6^{\circ} \mathrm{E}$ era o oposto, e foi apresentado aos PIBIDianos como sendo "uma turma muito problemática", composta majoritariamente por discentes que estavam repetindo o ano. OS PIBIDianos já havíam trabalhado com eles ao longo do primeiro semestre e os meses de agosto e setembro com alguns alunos para a feira de ciências, assim foi mais fácil à aceitação deste projeto na sala de aula por ambas as turmas. O desenvolvimento do projeto foi dividido em quatro etapas:

Primeira Etapa: As duas turmas foram divididas em dois grupos cada, nesta primeira fase eles jogavam entre si, competindo entre o próprio grupo, e sozinhos iram descobrindo as estratégias necessárias para ir avançando no jogo com o auxilio da maneira correta de utilizar o estilingue e fazer uso da força de gravidade específica para cada quadro ou "fase".

Segunda etapa: A cada semana eles jogavam e era explicado os três tipos de lançamentos (horizontal, vertical e obliquo) e sobre o que era gravidade e como ela estava agindo no jogo.

Terceira etapa: Foi realizado brincadeiras, onde era necessário o compreendimento de lançamentos para brincar. Jogos como vôlei, futebol, o uso de estilingue para determinar distancias entre outros.

Quarta etapa: Cada aluno realizou um pós-teste, onde respondiam três questões abertas, onde os alunos poderiam escrever ou desenhar. A primeira questão tinha dois estilingues, um mais esticado e outro menos, com ângulo de lançamento nitidamente diferentes. A segunda questão apresentava um menino jogando bola e uma menina que deveriam jogar algo no lixo e na ultima questão era solicitado para eles explicarem o que é gravidade. Depois, quatro alunos deste grupo foram sorteados para serem entrevistados.

\section{Resultado e Análise}

Para esta contribuição, escolhemos dois estudantes, um de cada uma das turmas, que demonstram o comportamento médio dos estudantes.

Durante a entrevista foi solicitado ao estudante que explicasse o porque das diferentes trajetórias que desenhou. A figura 1 abaixo ilustra as duas respostas. Observe que A1 (Figura 1, superior) desenha trajetórias respeitando os diferentes ângulos de 
lançamento, contudo as trajetórias não são bem previstas como a do A2 (Figura 1, inferior).
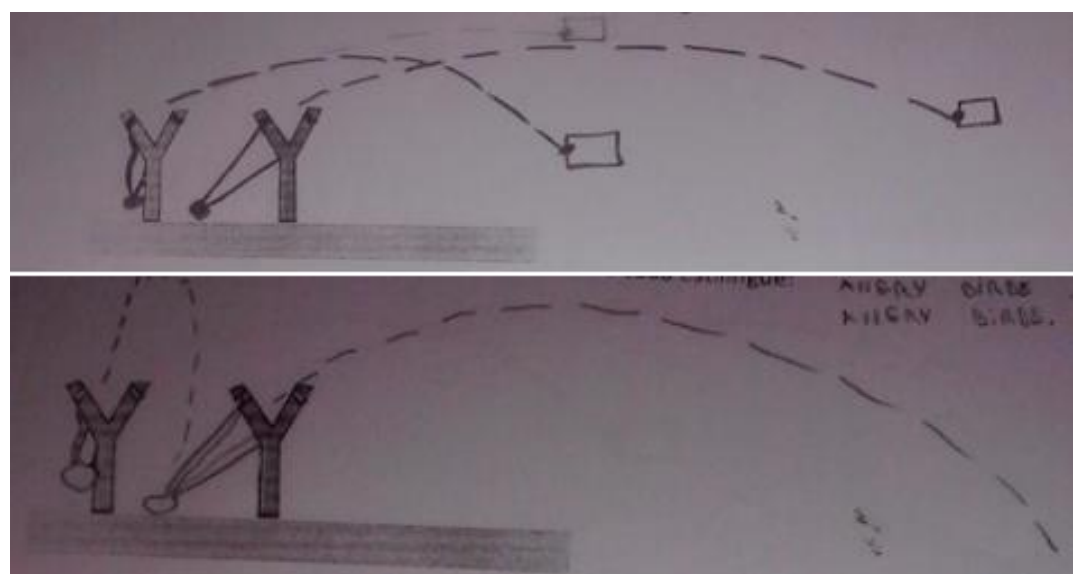

Figura 1 - Trajetórias previstas no teste escrito do estudante A1 (acima) e A2 (abaixo) no primeiro exercício.

A1, durante a entrevista:

"Este aqui eu achei que vai mais longe porque está mais esticado, e eu acho que vai mais longe e o outro não ta tanto, não vai tão longe, vai mais perto, até porque meus primos jogavam isso dai e eu sei.".
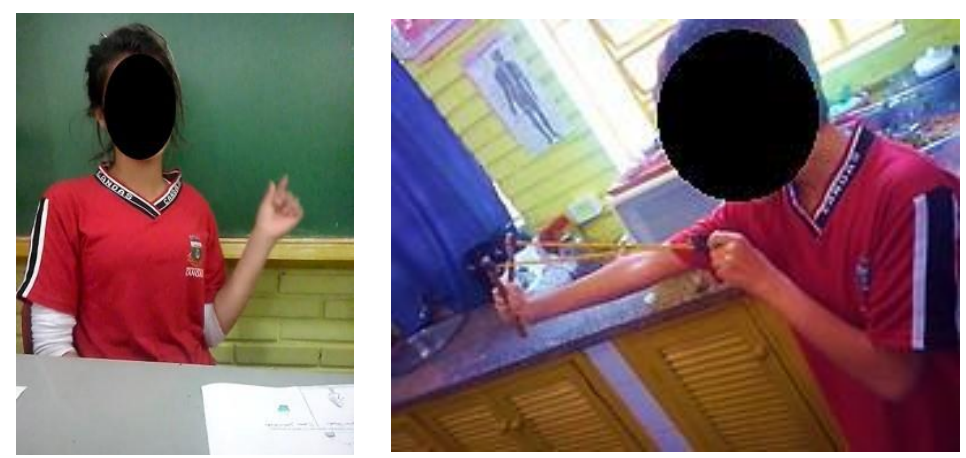

Figura 2: O gesto demostrado, mostra como o estilingue está mais puxado. Na segunda imagem, em uma das atividades, outro aluno com o estilingue.

Durante a explicação, o aluno produz um gesto indicativo de esticar um estilingue e lançar um objeto, o que indica a presença de uma imagem mental dinâmica internalizada sob a forma de um driver, ao interagir (observar) com objetos psicofísicos do ambiente. Os alunos também brincaram com estilingues durante a atividade (Figura 2)

Já o segundo aluno (A2), que desenha trajetórias mais consistentes, afirma que utiliza com frequência computadores e celulares para jogar, embora que não foi possível, durante a entrevista, identificar a fonte da imagem mental utilizada; acreditamos ser de origem de alguma interação hipercultural. 
A segunda questão foi colocada tentando identificar a capacidade do aluno de transformar seu conhecimento sobre trajetórias, em problemas que utilizam imagens muito próximas ao jogo Angry Birds Space (do estilingue) para situações do cotidiano.
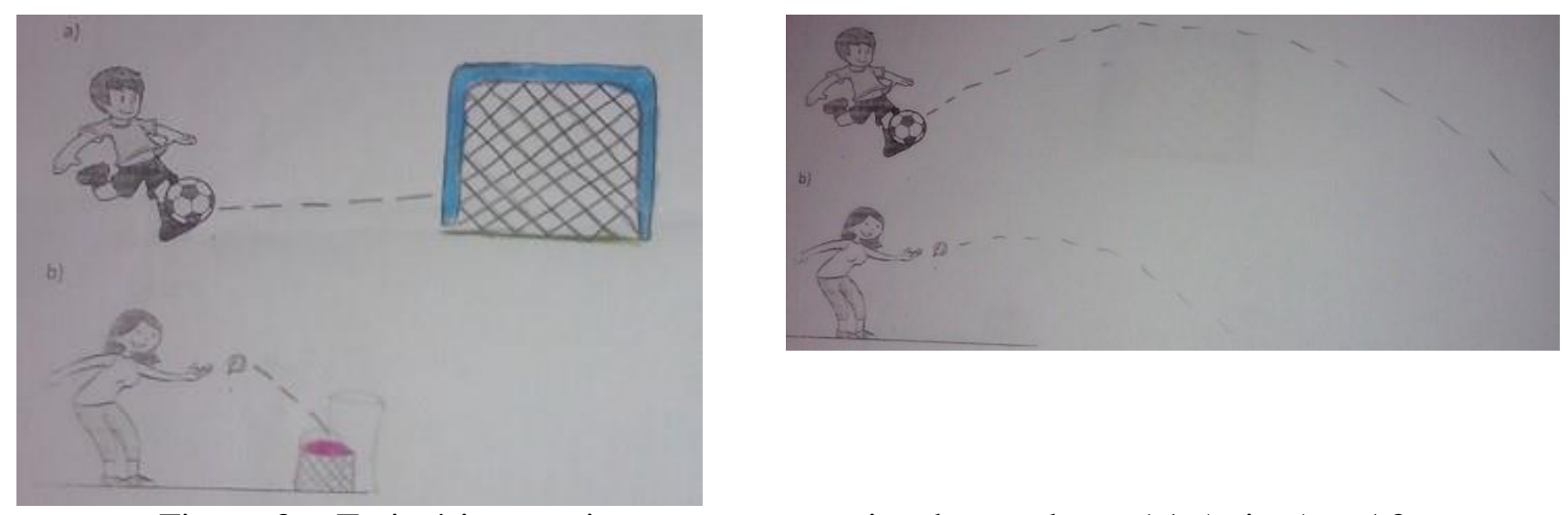

Figura 3 - Trajetórias previstas no teste escrito do estudante A1 (acima) e A2 (abaixo) no segundo exercício.

A figura 3 mostra o desenho de A1 (esquerda) e A2 (direita). Esta figura é consistente com o desenhado anteriormente, e mostra que as precisao das trajetórias em uma situação-problema semelhante ao jogo é transportada para uma situação diferente. Note que tanto a situação de trajetória de lançamento oblíquo quanto horizontal, em cada figura (parte superior e inferior, respectivamente) são melhores previstas por A2 do que por A1.

Continuando a entrevista de A1, ele nos mostra como seria trajetória da menina jogando algo no lixo e de como o menino jogaria a bola no gol e dizendo que apesar de já ter ouvido falar nos três tipos de lançamento, foi a partir do projeto que identificou cada tipo com o Angry Birds.

“...Já, mas eu sempre ouvi, mas não sabia muito bem que obliquo

é assim, que vertical era assim, e horizontal assim."

Já o estudante A2 não comenta sobre as trajetórias, ele possivelmente consideraas tão internalizadas como imagens mentais de medicações de diversos tipos (psicofísica, cultura e hipercultural) que não comenta a respeito na entrevista. Contudo, comenta que as trajetórias tem uma altura máxima e caem em seguida devido à "gravidade".

Finalmente, com relação ao conceito de gravidade, temos um diferença curiosa entre os dois estudantes. $\mathrm{O}$ estudante $\mathrm{A} 1$ menciona que:

“A1:Aí, porque com gravidade...aí pelo o que eu entendi com gravidade tu não fica flutuando, ai sem a gravidade tu fica, aqui eu desenhei umas pessoas e aqui uma xicara [Gesticula indicando algo flutuando], foi o que eu entendi. Entrevistador:Sim, uma xicara flutuando? A1:É. 
Entrevistador:Tu acha que a gravidade é sempre a mesma aqui e no espaço?

A1:Acho que não.

Entrevistador:Por que?

A1:Não sei."

Claramente A1 não adquiriu um conceito de gravidade, e podemos observar, na Figura 3 (à esquerda) que seu desenho muitas vezes ignora a trajetória parabólica descendente, apesar do contato com o jogo.

Finalizando a entrevista, A2 explica o que é gravidade para ele, e nos explica que é como se a gravidade fosse um grande imã que puxasse as coisas.

No decorrer do projeto, conversando com ele, percebemos que a origem desta concepção de gravitação advém de imagens mentais resultantes, conforme a TMC, de uma interação hipercultural com outro jogo que ele já jogou.

Entrevistador:E por que...e por qual motivo, eu vi nos dois desenhos, tanto nesse quanto nesse a pedra que foi atirada pelo estilingue cai. Por quê? Porque tu desenhaste nos dois ela caindo? O que faz ela cair no caso?

A2:Acho que a gravidade né.

Entrevistador:Gravidade, uhumm...e o que é gravidade para ti?

A2:Gravidade é para mim como se fosse uma imã no meio na Terra, puxasse as [gesticula como que puxando algo com a mão direita para baixo] aí elas caem.

A presença desta imagem mental da gravidade, apesar de não ser um conceito formado (até devido ao nível de ensino) é o suficiente para que o mesmo desenhe trajetórias surpreendentemente precisas, o que não acontece para A2.

\section{Conclusões finais}

Este estudo exploratório indica que a TMC oferece uma lente teórica interessante para se analisar o aprendizado de Física no nível fundamental, com a utilização de jogos de celular. O jogo Angry Birds Space aparentemente, de fato, contribui para que estudantes possam prever trajetórias e considerar ângulos de lançamento diferentes, através da alteração de suas imagens mentais e drivers. Contudo, caso o estudante (A1) não possua uma imagem mental da força da gravidade, as trajetórias podem ser simples, não serem parabólicas, e muitas vezes ignorarem a força gravitacional. O estudante A2, por exemplo, possui uma imagem mental simples advinda de um jogo de computador, mas que é suficiente para que suas trajetórias de lançamento horizontal e oblíquo sejam relativamente precisas. Nenhuma imagem mental da interação gravitacional foi advinda do uso do jogo. Contudo, deve-se observar que ambos os estudantes não desenvolvem um conceito aceitável da interação gravitacional. 


\section{Referencias bibliográficas}

CLEMENT, J. J.; STEPHENS, A. L. Documenting the use of expert scientific reasoning process by high school physics students. Physics Education Research, v. 6, n. 2 , p. 20122-1 - 20122-15, 2010.

EXTRA GLOBO. Professores utilizam Angry Birds para ensinar Física em sala de aula. Disponível em< http://extra.globo.com/noticias/educacao/professores-utilizamangry-birds-para-ensinar-fisica-em-sala-de-aula-2723541.html> Acesso em: 27 mai. 2014.

MONAGHAN, J. M.; CLEMENT, J. J. Use of a computer simulation to develop mental simulations for understanding relative motion concepts. International Journal of Science Education, v. 21, n. 9, p. 921 - 944, 1999.

MOREIRA, M. A. Pesquisa em Educação em Ciências: Métodos Qualitativos. Universidad de Burgos, Espanha; Universidade Federal do Rio Grande do Sul, Brasil. Texto de Apoio n 14. Publicado em Actas del PIDEC. Anais... p.4:25-55, 2002.

NEVES, M. C. D. Uma investigação sobre a natureza do movimento ou sobre uma historia para a noção do conceito de força. Revista Brasileira de Ensino de Física, v. 22, n. 4, 2000.

PEDUZZI, S.S.; PEDUZZI, L. O. Q. Leis de Newton: Uma forma de ensiná-las. Cad. Cat. Ens. Fís.v. 5, n.3, 1988

ROCHA, J. R.; SERRANO, A. Um Estudo de Caso Exploratório sobre a Internalização de Conceitos sobre Eletrostática: A influência da Hipercultura e Mediação Digital.

Revista Novas Tecnologias na Educação, v. 11, n. 3, p. 1-10, 2013.

ROONEY, A. The Story of Phyiscs. Rosen Publishing Group: New York, 2013.

SCIENTIFIC AMERICAN. Education Is for the (Angry) Birds. Disponível em < http://www.scientificamerican.com/article/education-is-for-the-angry-birds/> Acesso:02 jun. 2014.

SOUZA, B. C. DE. A Teoria da Mediação Cognitiva: Os impactos cognitivos da Hipercultura e da Mediação Digital, 2004. 282p, Tese (Doutorado em Psicologia) - 
Centro de Filosofia e Ciências Humanas, Universidade Federal de Pernambuco, Recife. Disponível em: <http://www.liber.ufpe.br/teses/arquivo/20040617095205.pdf> .

SOUZA, B. C.; SILVA, A. S.; SILVA, A. M.; ROAZZI, A.; SILVA, S. L. C. Putting the Cognitive Mediation Networks Theory to the test: Evaluation of a framework for understanding the digital age. Computers in Human Behavior, v. 28, n. 6, p. 2320 2330, 2012. Elsevier Ltd.

TERRA NOTÍCIAS. Angry Birds está a caminho das salas de aula brasileiras.

Disponível em < http://noticias.terra.com.br/educacao/angry-birds-esta-a-caminho-dassalas-de-aula-brasileiras, e98e78557aa5410VgnVCM3000009af154d0RCRD.html> Acesso em:02 jun. 2014.

VAN-SOMEREN, M. W.; BARNARD, Y. F.; SANDBERG, J. A. C. The Think Aloud Method: a practical guide to modeling cognitive processes. London: Academic Press, 1994. 